\title{
When Death Seems Suddenly Appealing, Defeated by the Long, Hard Struggle to Stay Alive
}

\author{
Anita Rego ${ }^{1, *}$, Chandra Ramamurthy ${ }^{2}$, Candice Menezes $^{3}$ \\ ${ }^{1}$ Pearls for Development, India \\ ${ }^{2}$ Kopal Trust, Vashi, Navi Mumbai, India \\ ${ }^{3}$ Tata Institute of Social Sciences, Deonar, Mumbai, India \\ *Corresponding Author: anitarego77@gmail.com
}

\begin{abstract}
Suicides are preventable with timely, low cost and evidence based interventions. The need of the hour- in developing countries like India where more than a hundred thousand lives are lost every year to suicide- is a national suicide prevention plan. Suicide prevention need to be approached through a holistic view where the existing public health care structures can complement the care and support needs of people who have attempted self-harm. This means that the existing systems need to be overhauled and integrated with a comprehensive mental health care plan, ensuring that all gatekeepers have access to suicide prevention education. This can be achieved by developing a key point access to the public health care system which will not only reduce the stigma and discrimination faced by individuals and their families- but ensure universal- physical and mental health care.
\end{abstract}

Keywords Suicide, Suicide Prevention, Key Access Point, Holistic Intervention

\section{Introduction}

Globally suicides account for $50 \%$ of all violent deaths in men and $71 \%$ in women. For every suicide- there are many more people who attempt suicide every year. Yet, suicide is a serious public health problem; the developing world is witness to three quarters of suicides that is seen globally. The Sixty-sixth World Health Assembly adopted the first-ever Mental Health Action Plan with the goal of reducing the rate of suicide in countries by $10 \%$ by 2020 in May 2013 . Ironically, we are far from reaching anywhere close to it. In India the number of suicides in the country during the decade (2004-2014) has recorded an increase of $15.8 \%(1,31,666$ in 2014 from 1,13,697 in 2004) (NCRB, 2014). The age standardised suicide rate in India is 14.3 suicide deaths per 10,000 population for women and 17.1 suicide deaths per 10,000 population for men (WHO India country data 2017).
In India, there is stigma attached to mental illness as well as suicide. The reactions to those who commit suicide are mixed. Among several misconceptions surrounding suicide, the common ones are: there are no warning signs to suicide, talking about suicide may encourage suicide ideation, suicide is a mere cry for attention, mostly young people attempt suicide and there is not much one can do to help those who are serious about committing suicide; these very misconceptions are extremely critical in identifying and preventing suicide. It is not unnatural that people do reach a breaking point in their lives, and this has very little to do with their gender, age or sexual orientation. India has now joined the nations who have decriminalised suicide, however, on the ground nothing much has changed and people are yet to accept that attempted suicide is no longer a crime in the country.

\section{Why do People Commit Suicide?}

The risk of a person contemplating, attempting or committing suicide is one that can never be taken lightly nor ever be ignored. There is no single explanation or reason for why people commit suicide. Both, psychological causes and social causes are commonly associated with suicides. While the link between suicide and mental disorders (in particular, depression and alcohol use disorders) is well established in high-income countries, many suicides happen impulsively in moments of crisis with a breakdown in the ability to deal with life stresses, such as financial problems, relationship break-up or chronic pain and illness.

In addition, experiencing conflict, disaster, violence, abuse, or loss and a sense of isolation are strongly associated with suicidal behavior. Suicide rates are higher than the general population rates amongst vulnerable groups who experience discrimination, such as refugees and migrants; indigenous peoples; lesbian, gay, bisexual, transgender, intersex (LGBTI) persons; and prisoners. By far, the strongest risk factor for suicide is a previous suicide attempt (WHO, 2008). 
In India, youth (18 and above-below 30 years) and middle aged people ( 30 and above- below 45 years) are the prime groups taking recourse to the path of suicides. These age groups account for $34.1 \%$ and $32.2 \%$ suicides respectively. Other family problems (245), illness (181) and failure in examination (163) are the main causes of suicide among children (below 14 years of age) (NCRB, 2014). This data further showcases an alarming trend among youngsters who believe that suicide is the only response to a problem.

In India, other family problems and illness are attributed as the major causes of suicide, accounting for $21.7 \%$ and $18.05 \%$ of the total suicides. Unemployment $(1.7 \%)$, poverty $(1.3 \%)$, property disputes $(0.8 \%)$ and death of a dear one $(0.7 \%)$ are the 'other' causes of suicide (NCRB, 2014).

\subsection{Sociological Perspectives on Suicide}

In his book Suicides (Baechler, 1979), Jean Baechler opined that suicides can be a valid, rational action and should neither be considered as a sociological aberration nor condemned as madness. People are most driven to suicide when they view their current situation as being completely hopeless and feel as if they have no way to change things for the better. According to him, suicide is not only a response to a problem but also a method or a mean to resolve it (Rogow A.A, 1979).

In 1897, in a book Le Suicide, French sociologist Émile Durkheim (Durkheim, 1897) described suicide as a result of social disorganisation or lack of social integration or social solidarity. In 2014, an agrarian country like India, reported 5,650 farmer suicides. High debts, risky credit systems, the failure of monsoons, the government's economic policies etc. are some of the factors that have led to an increase in suicide rates among farmers. Left to their own devices, social isolation combined with a lack of support from the government or any other agency continues to fuel suicides amongst farmers in rural India.

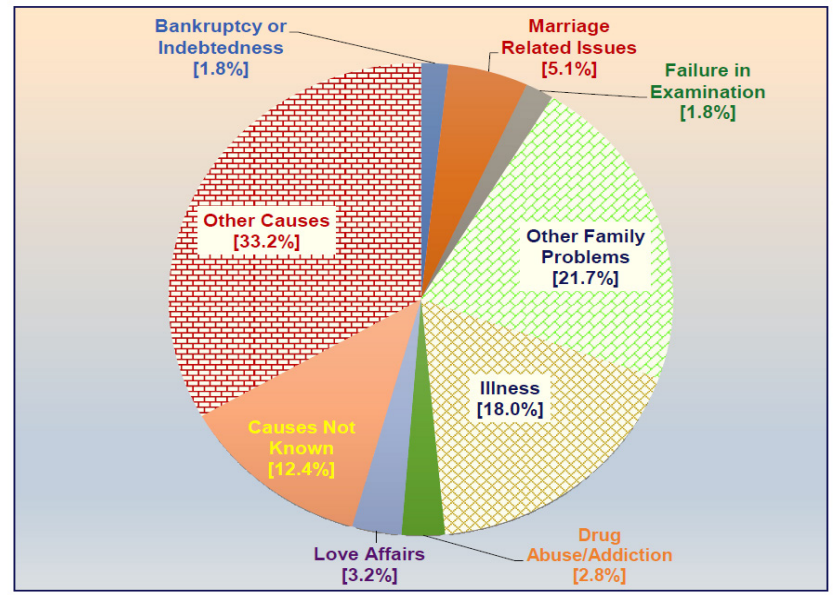

Figure 1. Percentage share of major causes of suicide in India in 2014 (NCRB, 2014)

The wide range of reasons that make people resort to suicide are more varied and complicated than usually thought. They also differ from region to region. The reasons behind suicides can be linked to physical changes that manifest in behavioural changes and also changes in affect.

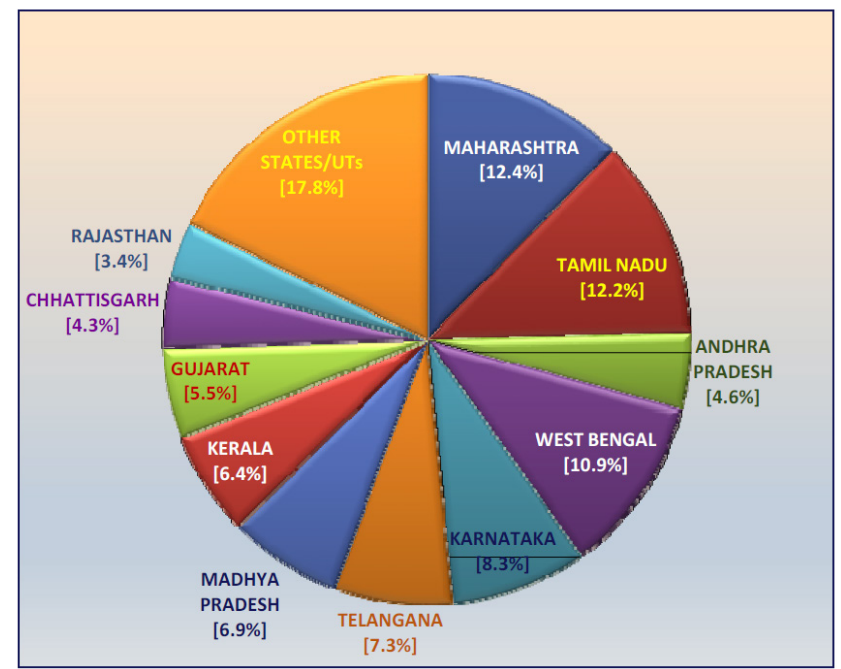

Figure 2. State/UT wise percentage of suicide in India during 2014 (NCRB, 2014)

Physical indicators (Figure 3) like prolonged illnesses, chronic fatigue, lack of interest in self, or in life are strongly linked to behavior (Figure 4) like recklessness or withdrawal or even self-harm. These are sometimes accompanied by feelings (Figure 5) of hopelessness, worthlessness, guilt, sadness and even helplessness.

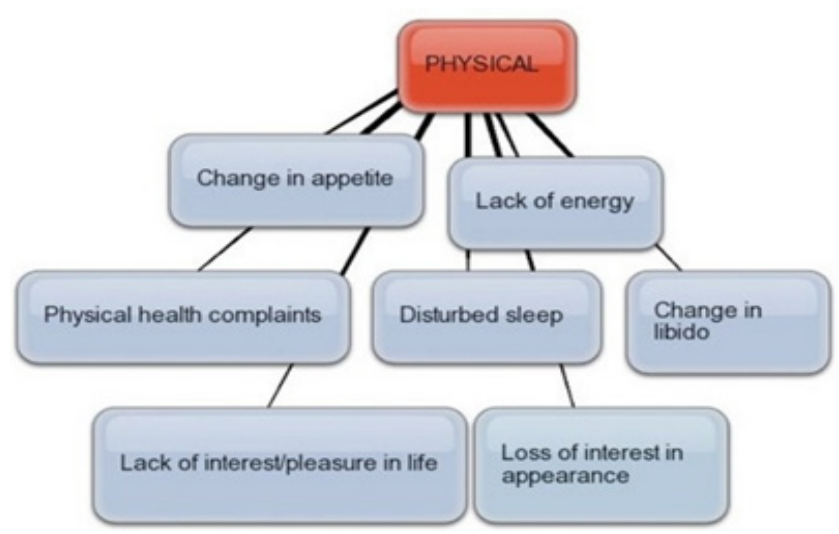

Figure 3. Physical changes

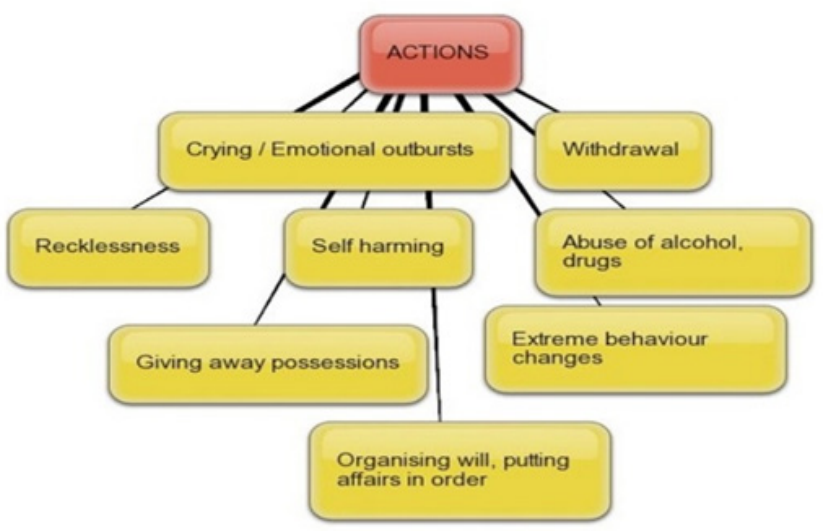

Figure 4. Behavioral changes 


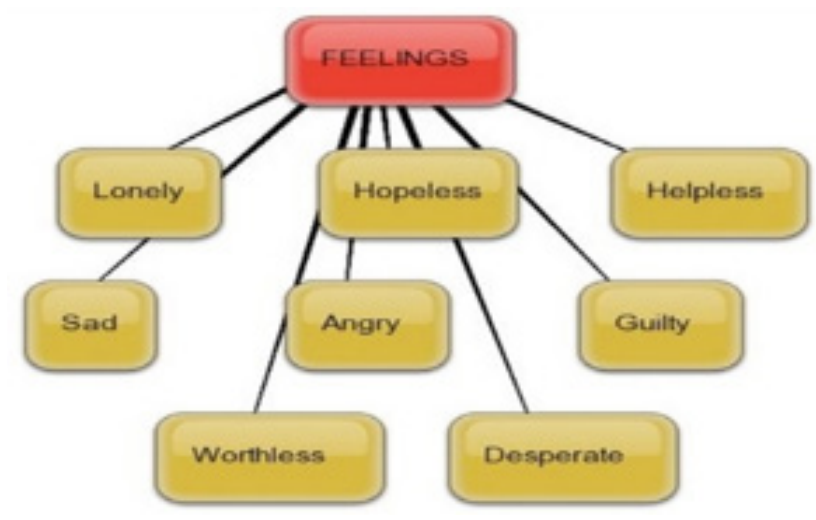

Figure 5. Changes in affect

The crux of any intervention is to listen or check for the message. A suicidal person may not ask for help, but that doesn't mean that help is not wanted. Most people who commit suicide do not want to die-they just want to stop hurting. The crisis hotlines for suicide, a step in this direction, has been effective in making the last attempt to prevent the distressed person from taking an action on his life, against a realization that the jury is out there questioning on whether they even help (Mental Health Blog, 2014)

\section{What Can Be Done to Prevent it?}

Suicide prevention starts with recognizing the warning signs of suicide and taking them seriously. If you think a friend or family member is contemplating suicide, you might be afraid to bring up the subject. But talking privately and openly to a person considering suicide affords the opportunity for him/her to express his/her feelings and can provide relief from loneliness and pent-up negative feelings. It may even help prevent a suicide attempt (Schmidt P. G, 2012). Some ways to start a conversation can be "I have been feeling concerned about you lately", "I have noticed some differences in you recently and was wondering how you are doing?" "I wanted to check with you as you haven't seemed yourself lately." It is also beneficial to have information on help lines and support groups handy so that the person can be referred to help immediately. What is of utmost importance is that person's immediate safety.

It's important to evaluate the immediate danger the person is in. Those at the highest risk for committing suicide in the near future have a specific suicide plan, the means to carry out the plan, a time set for doing it, and an intention to do it. Some of the questions that can be asked to assess this are "Do you have a suicide plan?", "Do you have what you need to carry out your plan (pills etc.)?”, "Do you know when you would do it?", "Do you intend to commit suicide?" It is always useful to rule out any psychiatric problems and explore for personality related triggers leading to the suicide attempt.

The first step is always to calm the person down. Next, one needs to assess the need for first aid/medical attention if necessary. The person attempting suicide needs to be provided immediate emergency mental health services, and arrangements need to be made for providing consistent emotional and psychological and psychiatric support for the next few days. The individuals' desire to live needs to be strengthened and he/ she can be guarded from relapse/ deliberate self-harm, with arrangements made for a safety anchor/a back-up plan. Correct and timely psychiatric care and a supportive environment is vital for not only the person contemplating, attempting or committing suicide but also for the extended family members who have to deal with the repercussions of the same. Changes in family dynamics and even societal pressures need to be addressed in safe environments. The strategies for each of the above will vary from person to person and also depend on the triggers for suicide.

Apart from evidence based interventions and simple strategies suggested by psychologists as mentioned above, it is also important to initiate universal prevention strategies to maximize health and minimize suicide risk, by removing barriers to care and increasing access to help, strengthening protective processes such as social support and altering the physical environment.

Individuals attempting suicide can be linked with suicide support groups, suicide prevention help lines and their social support systems can be strengthened. Treating or caring for these individuals in isolation is not very helpful. Family members, friends and even caregivers can be taught about risks and warning signs and also how to seek help. Social support can be strengthened not only for the individual attempting suicide, but also for family members/friends who have survived or are bereaving a suicide attempt. Marital and family counseling services can be made available alongside group strategies for suicide prevention. A good suicide prevention program requires a multi-sectoral integrated / holistic approach that will encompass all these and more.

\section{Integrated Approach to Suicide Prevention}

In India, until recently, attempting suicide could attract a maximum punishment of imprisonment for one year according to Section 309 in the Indian Penal Code (11). In 1996, a five judge bench of the Supreme Court of India had ruled that the section 309 was not violative of article 21 of the Constitution of India which guarantees the Right to Life and the Right to Personal Liberty. The Rajya Sabha (the upper house of the Parliament in India) on August 8, 2016 decriminalized the Offence of Attempt to Suicide by passing Mental Healthcare Bill (Section 309, IPC). In April 2011, the Ministry of Health and Family Welfare (MoHFW) created a Policy Group, to prepare a National Mental Health Policy and Plan (The Mental Health Care Bill, 2016). This policy group was entrusted with the task of re-designing the District Mental Health Plan (DMHP) as a matter of priority to be 
ready for the Twelfth Five Year Plan period (MoHFW 2012). The DMHP aims at reduce distress, disability and premature mortality related to mental health problems and enhance recovery from mental health problems by ensuring the availability of and accessibility to mental healthcare for all (Shidhaye R and Patel V, 2014).

In spite of the changes in the law and initiatives to develop a robust District Mental Health Plan, stigmatization of and discrimination against people with mental health problems is still common in India, in all sections of society, from community to schools, work-place and even healthcare settings. This stigma and discrimination presents formidable barriers both to social inclusion for affected people and their families, and to access to appropriate healthcare.

Interventions for suicide prevention are changing but it is very important that people are aware and are taught to deal with underlying issues that either push people to suicide or are associated with it. The need of the hour is to establish and sustain systems that will provide a holistic and supportive environment to help those who at risk or attempt suicide and provide them with a continuum of care and support that they need rather than label them, criminalize their act and isolate them.

\section{Role of Primary Health Care Services}

In India, suicide prevention can be integrated effectively and easily in government run public health programs. Primary health care providers, doctors (practitioners of Allopathy, Homeopathy and Ayurveda) educators, police and other gatekeepers can be trained to identify and respond to the warning signs of suicide (SPRC, 2017). After even minimal training, staff can observe warning signs of suicide in patients while talking with them on the phone or in the office, detect warning signs, and can immediately alert office clinicians who are prepared to ask the patient about suicidal ideation. Though these trainings require a modest investment of time and money, they may save lives. Introducing a component of mental health care in all curriculums can also limit the scope of self-harm among the vulnerable population.

Government and non-government agencies can help educate patients and their families and restrict access to means of lethal self-harm- by removing knives, guns, poisons, dangerous medicines and acids that make suicides easier. Awareness campaigns can be run that will help reduce the stigma associated with suicide and raise public awareness about one of the most critical public health problems that we face this century.

\section{Creating a Key Point Access to All Health Services}

All health services can be bundled and linked to community wellness centers or public health centers- to give one key point of accessibility to all population. Improving access to mental health services is necessary but physical manifestations like headaches can also be linked to mental health issues. These are often swept under the carpet or go largely unnoticed and unreported. These symptoms or physical manifestations can be examined in a non-threatening, non-stigmatized environment, in a public health centre or similar facility if found appropriately linked to a more dangerous precondition for self-harm.

People may need early intervention in a non-stigmatized environment that may provide group strategies as well as selective prevention strategies for target vulnerable groups. The key point access to health service also include crisis intervention centers and post intervention centers that can help with care and support for the individual and the family members, teaching them to cope with the aftermath of an attempt of suicide.

\section{Creating an Enabling Environment}

The holistic approach also recommends that school/educational, work environments and religious organisations also be involved in suicide prevention work. Schools, colleges and work institutions can help strengthen the person's problem solving, conflict resolution and coping skills to deal with life situation better. These institutions can organise suicide awareness activities and encourage people to live life to its full potential and capacities.

Organisations can also work with police forces and the judiciary to decriminalise suicide, advocate for sensitive laws and policies for inclusion and demand for better access to mental health care services.

\section{Role of Media}

Media can play a powerful role in demystifying suicide. Responsible reporting of suicide in the media has been shown to decrease suicide rates. Important aspects of responsible reporting include: avoiding detailed descriptions of suicidal acts, avoiding sensationalism and glamorization, using responsible language, minimizing the prominence of suicide reports, avoiding oversimplifications, educating the public about suicide and available treatments, and providing information on where to seek help (SPRC, 2017).

Media advocacy can be a useful tool in helping people celebrate differences. National and local campaigns can be run by media to highlight mental health issues and encourage responsible and ethical reporting of suicides (Samaritans, 2013). Above all, we all can contribute individually and collectively to respect the rights of people.

Celebrities, societal leaders and influential politicians can play an important role in de-stigmatizing mental illness. In India, Deepika Padukone, a famous Bollywood actress, stunned her fans by admitting that she had been suffering from anxiety and depression. This move was bold considering she broke this news at a time when she was one of the most sought after actresses in Bollywood (Srivastava 2016). This was also noteworthy as mental illness is not 
talked about in Indian society. With more celebrities becoming candid about their mental health issues, one can only hope that there is more awareness towards mental illness and a responsible move to help prevent the increasing cases of self-harm.

\section{Conclusions}

Suicide impacts the most vulnerable of the world's populations and is highly prevalent in already marginalized and discriminated groups of society. It is not just a serious public health problem in developed countries; in fact, most suicides occur in low- and middle-income countries where resources and services, if they do exist, are often scarce and limited for early identification, treatment and support of people in need.

These striking facts and the lack of implemented timely interventions make suicide a global public health problem that needs to be tackled imperatively (WHO, 2014). There is an urgent need to develop a national plan for suicide prevention especially in a developing nation like India where suicide imposes a huge social, emotional and economic burden on the society.

Suicide prevention can be efficiently addressed by enabling government and non-government organizations to adopt a holistic approach to suicide prevention- by integrating suicide prevention education, and care and support systems across multiple channels and strengthening the existing public health care systems to recognize and address the issue of self-harm.

\section{REFERENCES}

NCRB (2014). Suicides in India, Retrieved from http://ncrb.nic.in/StatPublications/ADSI/ADSI2014/chapter-2\%20 suicides.pdf

WHO India Country Data (2017). Crude suicide rates per 100,000 population, WHO India country data last updated 4/4/2017.

Retrieved from

http://apps.who.int/gho/data/node.main.MHSUICIDE?lang=en

WHO (2008). Preventing suicide - A resource for Media Professionals. Retrieved from

http://www.who.int/mediacentre/factsheets/fs398/en/

NCRB (2014). Suicides in India, Retrieved from http://ncrb.nic.in/StatPublications/ADSI/ADSI2014/chapter-2\%20 suicides.pdf
Baechler J. (1979) Suicides (1979), Basic Books, New York City. Retrieved from Understanding Suicide and its Prevention- A Neuropsychological approach, Federico Sanchez, Xlibris Corporation 2010.

Rogow A.A. (Sept 23, 1979). A very personal matter. Retrieved from

http://www.nytimes.com/1979/09/23/archives/a-very-personal-mat ter-suicide-authors-query.html? r=1

Durkheim E (1897). Le Suicide (1897). Retrieved from http://durkheim.uchicago.edu/Summaries/suicide.html

Mental Health Blog (n.d). 15 Common Causes of Suicide: Why Do People Kill Themselves?

http://mentalhealthdaily.com/2014/07/23/15-common-causes-of-su icide-why-do-people-kill-themselves/

Schmidt P. G. (2012) Suicide Prevention- Veterans Module (2012), Retrieved from

http://www.doh.wa.gov/Portals/1/Documents/2300/2016/689Non DOH.pdf

Section 309 in the Indian Penal Code. Indian Kanoon. Retrieved from

https://indiankanoon.org/search/?formInput=offence $\%$ 20under $\% 2$ 0section $\% 20309 \% 20$ of $\% 20$ indian $\% 20$ penal $\% 20$ code on 15 July 2014

The Mental Healthcare Bill 2016. As passed by the Rajya Sabha on $8^{\text {th }}$ August 2016. Retrieved from

http://www.prsindia.org/uploads/media/Mental\%20Health/Mental $\% 20$ health\%20 care\%20as\%20passed\%20by\%20RS.pdf on 5 May 2017

Shidhaye R and Patel V (2014). Shidhaye R and Patel V. Improving access to mental healthcare in India: Opportunities and innovations. Retrieved from

https://www.idfc.com/pdf/report/2013-14/Chapter-18.pdf on 5 May 2017

Suicide Prevention Resource Centre. (n.d.). Module 3 - Effective Prevention Strategies Retrieved from http://www.sprc.org/sites/def ault/files/PrimerModule3.pdf on 5 May 2017

Samaritans (2013). Media Guidelines for Reporting Suicide, Guardian News and Media Limited (2013). Retrieved from http://www.samaritans.org/sites/default/files/kcfinder/files/press/S amaritans\%20Media\%20Guidelines\%202013\%20UK.pdf on 5 May 2017

Srivastava D. (2016) Our silent relationship with mental health: Stigma is still strong in India. 24 April 2016. Retrieved from http://www.firstpost.com/living/our-silent-relationship-with-menta 1-health-stigma-is-still-strong-in-india-2739554.html on 5 May 2017.

WHO 2014. Preventing Suicide: A Global Imperative, WHO 2014. Retrieved from

http://www.who.int/mental_health/suicide-prevention/world_repor t 2014/en/ on 5 May 2017. 